\title{
ethic @ \\ A TRANSFORMAÇÃO DA FILOSOFIA \\ ENTRE A REFLEXÃO TRANSCENDENTAL E A \\ RECONSTRUÇÃO RACIONAL: SOBRE O SENTIDO DE UMA CONTRAPOSIÇÃO FILOSÓFICA CONTEMPORÂNEA
}

\author{
THE TRANSFORMATION OF PHILOSOPHY \\ BETWEEN TRANSCENDENTAL REFLECTION AND RATIONAL \\ RECONSTRUCTION: ON THE MEANING OF A CONTEMPORARY \\ PHILOSOPHICAL CONFRONTATION
}

\author{
LUIZ REPA ${ }^{1}$ \\ (USP/Brasil)
}

\begin{abstract}
RESUMO
O artigo pretende mostrar as diferenças fundamentais entre os projetos de Habermas e Apel de transformar a filosofia. Essas diferenças podem ser medidas por meio de uma comparação entre os conceitos de reflexão transcendental em Apel e de reconstrução racional em Habermas. Baseando-se nessas diferenças, é possível afirmar que a transformação da filosofia em Apel se limita a dar uma outra forma à tentativa da filosofia primeira de estabelecer uma fundamentação última para si e para as ciências, ao passo em que o conceito habermasiano de reconstrução confere à filosofia o papel, mais inovador, de guardar o lugar para teorias científicas e interpretar os desenvolvimentos científicos e culturais.
\end{abstract}

Palavras-chave: Apel; Habermas; Reflexão Transcendental; Reconstrução Racional; Transformação da Filosofia.

\begin{abstract}
The article aims to show the fundamental differences between Habermas's and Apel's projects to transform philosophy. These differences can be measured by comparing Apel's concept of transcendental reflection and Habermas's method of rational reconstruction. Based on these differences, it is possible to state that the transformation of philosophy in Apel's thought means to give another way to the attempt by first philosophy to establish an ultimate foundation for itself and the sciences while the Habermasian concept of reconstruction assigns philosophy the most innovative role of stand-in for scientific theories and interpreter of cultural developments.
\end{abstract}

Keywords: Apel; Habermas; Transcendental Reflection; Rational Reconstruction, Transformation of Philosophy. 
Já se disse que a "disputa em família", expressão com que Jürgen Habermas tentou minimizar suas divergências com John Rawls no âmbito da teoria da justiça e da democracia, nunca deixou de conter princípios de incêndio, como toda boa briga de família (cf. HABERMAS, 2018, 108). Algo semelhante se poderia falar das diversas contraposições que Karl-Otto Apel direcionou a seu ex-aluno e amigo de vida toda. Aparentemente desvios internos de projetos que convergiam para um mesmo horizonte filosófico, essas contraposições abrigam, na verdade, disputas de longe alcance sobre o sentido da filosofia na cena contemporânea.

É verdade que tanto Habermas quanto Apel se comprometem com a tarefa de transformar a filosofia com base na filosofia da linguagem ou na "linguistic turn", seja por uma derivação da teoria wittgensteiniana dos jogos de linguagem pela pragmática formal como no primeiro, seja por uma semiótica ou pragmática transcendental baseada em Wittgenstein e Peirce, como no segundo. Ambos, além disso, querem renovar a filosofia por um novo tratamento da perspectiva transcendental kantiana. Soma-se a isso o projeto comum de elaborar e fundamentar a ética do discurso, recuperando o princípio de universalização da moral kantiana. No entanto, tais intentos de transformar a filosofia e as concepções normativas que eles pressupõem acabam se colidindo entre si, por mais que Ihe sejam comuns os suportes e as referências teóricas. Eu gostaria de aprofundar essas divergências a partir de duas noções caras a cada um deles.

O conceito de reflexão transcendental, "crítico do sentido", de Apel está a serviço de uma fundamentação última da racionalidade linguística, que não esconde sua filiação com as intenções da filosofia primeira (APEL, 1973c, 1994a, 1994b, 1985). Nesse contexto, pretendo mostrar que, por mais que Apel se valha dos pressupostos pragmáticos da fala, é no momento da certeza reflexiva de si mesmo que o discurso filosófico como filosofia primeira se alça e ganha o seu sentido suficiente. Diferentemente, o conceito habermasiano de reconstrução só pode se valer das estratégias abertas pela reflexão apeliana, a saber, a contradição performativa, como alguém que tateia a razão não no sujeito linguisticizado mas na realidade fugidia do mundo da vida das sociedades modernas.

Mais concretamente, as diferenças entre a reflexão transcendental de Apel e a reconstrução racional de Habermas se apresentam nos tipos de discurso que a filosofia pode exigir para si diante da ciência, da cultura e da sociedade na modernidade. A reflexão quer fundamentar princípios científicos e éticos, estabelecendo um espaço bem definido e autossuficiente para a filosofia, a reconstrução quer guardar o lugar e interpretar os desenvolvimentos das ciências e os processos mais amplos da sociedade, seu curso factual no horizonte das possibilidades reais. Sem dúvida, a 
reflexão apeliana recorre à ideia de reconstrução racional e mesmo parece se confundir eventualmente com ela (cf. APEL, 1973a, 383, 420), assim como a reconstrução habermasiana se entende desde a primeira hora como reflexão (quase-) transcendental (cf. HABERMAS, 2014, 491 ss.). No entanto, o objetivo de transformar a filosofia toma cursos inteiramente diferentes. A transformação da filosofia deve ser apenas uma outra forma de filosofia primeira em Apel, embora superior e de certo modo abrangendo os paradigmas anteriores da ontologia antiga e da epistemologia moderna; no caso de Habermas, ela recobra, sem dúvida, algo da teoria sistemática da racionalidade, mas, como reconstrução, não pode reivindicar nenhuma certeza definitiva, nenhum tribunal para a ciência e a cultura, restando-Ihe o papel crítico de identificar possibilidades não realizadas na modernização e de mediatizar ciência, moral e arte entre si e o mundo da vida.

A seguir, pretendo sustentar essa linha de diferenciação a partir do papel que a certeza do sujeito de argumentação como resultado da reflexão desempenha ainda na filosofia apeliana, que completa o sentido da fundamentação última como pensamento ao mesmo tempo linguisticamente estruturado e autorreferido (I), para depois confrontar a proposta habermasiana, que recusa a certeza em nome de uma plausibilidade a ser conquistada com as ciências, com as artes e com o mundo da vida de modo geral (II).

\section{$\mathbf{I}$}

A ideia de transformação da filosofia é cara tanto a Apel, que fez dela o título de uma de suas duas principais obras, como a Habermas, que parte da concepção de filosofia como crítica da ideologia para desenvolver posteriormente seus papeis de guardador de lugar e intérprete. No entanto, desde cedo, apesar das semelhanças, o objetivo de transformar a filosofia responde a questões e toma direções muito diferentes. Essa circunstância já se apresenta na remissão à pretensão jovem-hegeliana de superar a filosofia por meio de sua realização (MARX, 1970; KORSH, 2008). Porém, enquanto esse motivo se prolonga em Habermas ao longo dos anos sessenta e determina até certo ponto a obra madura (HABERMAS, 2013, 2000; NOBRE, 2000), em Apel ele é retomado no início do primeiro volume de $A$ transformação da filosofia (1973) 2 para ser rapidamente invalidado. A filosofia, pensa Apel, não pode ser ela mesma a forma de uma sociedade emancipada: realizar a filosofia esconde um engodo sobre a comunidade dos filósofos, que espelha, como toda associação humana, os interesses e os partidos da sociedade histórica. Aqueles que partem para a realização política da filosofia, por outro lado, incorrem em uma dogmatização política 
que torna impotente ou dispensável a filosofia como discurso teórico sobre o "consenso ideal" da humanidade emancipada (APEL, 1973a, 11). Mesmo que o último e certamente o mais importante estudo sobre "O a priori da comunidade de comunicação" retome em seu fim o tema da realização da filosofia, é para defender a tese de que ela somente pode se orquestrar a partir daquele discurso, em especial no que diz respeito aos fundamentos éticos do marxismo (APEL, 1973d, 432).

Para Apel, é preciso livrar a filosofia de visões de mundo que foram próprias dos grandes pensadores, em favor do delineamento dos critérios, dados pela teoria, à ação prática. A transformação da filosofia tem a ver com a perda de autoridade da grande filosofia em ministrar visões de mundo. Essa observação é importante porque permite estabelecer que, de acordo com Apel, a transformação da filosofia é algo também em curso, para o qual ele próprio contribui, ao mesmo tempo uma reconstrução histórica e um projeto filosófico. As exigências jovem-hegelianas de superar a filosofia não ameaçam de fato a convicção de que o discurso filosófico pode reivindicar uma continuidade como filosofia primeira, embora precise de ajustes, capazes de suplantar a caducidade dos "grandes pensadores" sem perder sua substância. Em correlação com isso, o próprio tema da transformação da filosofia recebe, a partir do segundo volume, uma complementação por assim dizer natural: a transformação passa a referirse de modo geral à filosofia transcendental.

A ameaça vem, isso sim, da cientificização, da caducidade a que a racionalidade científica condena (também no marxismo) o discurso filosófico em suas pretensões mais enfáticas, reduzindo-o a uma teoria das ciências de curto alcance, minando ainda mais as possibilidades da filosofia prática no momento em que a civilização técnico-científica representa ela mesma uma ameaça à vida humana (APEL, 1973d, 361). A objetividade axiologicamente neutra define de antemão toda ideia de validade, e justamente por isso se complementa com o subjetivismo existencial quando ao caráter privado e em última instância decisionista sobre os fundamentos das normas éticas (APEL, 1973d, 370). Ainda que se refine ao longo dos ensaios reunidos nos dois volumosos livros de $A$ Transformação da filosofia (1973), o diagnóstico fundamental se refere sempre ao objetivismo científico e ao subjetivismo ou relativismo moral como seu correlato. Não é de estranhar, então, que Apel tenha em mira, desde o início e ao longo de sua obra, o racionalismo crítico popperiano, na medida em que este, na base de um conceito dedutivista de fundamentação, recusa a possibilidade de uma fundamentação para a si mesmo como epistemologia e de uma fundamentação para a moral - ou seja: da filosofia em geral - e, ao mesmo 
tempo, contém o princípio de sua própria superação como recurso estruturante a uma forma especial de argumentação.

Certamente, o enfrentamento com o racionalismo crítico se vale da interpretação que o editor alemão da obra de Peirce imprimira à semiótica. $\mathrm{Na}$ "era da ciência", a filosofia poderia encontrar uma nova base no modo linguístico da obtenção de consenso na comunidade dos cientistas, como Peirce pensa as condições da verdade, sem se render ao cientificismo. Portanto, a transformação da filosofia "ligada às ciências" deve passar por uma "concretização do sujeito transcendental de Kant", recorrendo à concepção peirciana da formação de consensos na comunidade dos pesquisadores (APEL, 1973a, 12).

Com essa abordagem, o método da argumentação crítica desenvolvido pela escola popperiana poderia ser aproximado da concepção peirciana e, com isso, voltado às objeções dessa mesma escola contra a possibilidade de uma fundamentação última de padrões de racionalidade não restritos à cientificidade, contra o "profundo preconceito" a respeito de uma ampliação da racionalidade.

Com uma tal abordagem no plano da comunicação interpessoal, seria dado, a meu ver, um passo essencial rumo à ampliação do conceito de racionalidade e, com isso, ao programa de uma transformação da filosofia ligada à ciência (APEL, 1973a, 19).

Nesse contexto, Apel também deixa clara sua intenção de reestabelecer um porto seguro para a racionalidade da argumentação ampliada: "não se pode entender a filosofia simplesmente como 'crítica', sem se certificar dos próprios critérios, ou seja, das condições de possibilidade e validade da crítica" (APEL, 1973a, 22). Essa objeção contra o racionalismo crítico popperiano pode ser tomado, na verdade, como um lema para a restauração do conceito de razão em toda a sua amplitude, incluindo aí as contribuições para a ética ou para a crítica social (APEL, 1973b). A filosofia primeira, assim reformada, deve assegurar o fundamento do critério da crítica antes mesmo de pôr-se a criticar seu objeto.

É interessante observar como esse desiderato se satisfaz mesmo com as consequências hermenêuticas que Apel deriva imediatamente da transposição da comunidade de comunicação transcendental para os processos comunicativos reais, carentes de um acesso hermenêutico. Seguindo Heidegger e Gadamer, Apel dirá que a comunicação impõe um procedimento de compreensão [Verstehen] que não está à simples disposição dos intérpretes e que, nesse sentido, são "quase 
transcendentais". Com cuidado, ele reconstitui toda a história da hermenêutica e da fenomenologia contemporâneas para identificar a perda do vínculo entre condição de possibilidade e validade, de compreensão e fundamento, em que se refletiria a continuidade do questionamento kantiano depois do abandono do sujeito transcendental enquanto tal. A hermenêutica apeliana pode se entender então como uma "hermenêutica transcendental" que tem como questão fundamental a "'pré-estrutura' da compreensão para todas as formas de conhecimento científico e précientífico" (APEL, 1973a, 44). Pela questão do acesso hermenêutico se poderia, então, fazer o elo entre a comunidade dos cientistas, dos interpretes, mas também dos interpretados, os sujeitos culturais socializados por meio da linguagem. Por outro lado, o encontro dessa préestrutura permitiria restringir a pretensão de universalidade da hermenêutica, como Gadamer a propõe, fundamentando-a normativamente (APEL, 1973d, 389; HABERMAS, 1982). Pois nesse caso o processo de interpretação já é antecedido do conjunto de pressuposições que garantem "o ideal normativo do entendimento" (APEL, 1973d, 390).

Tal pré-estrutura da compreensão constitui a comunidade ideal de comunicação: os pressupostos pragmático-transcendentais da linguagem que orientam a priori os participantes a obter um consenso "como entendimento linguístico do sentido linguístico como verdade possível" (APEL, 1973a, 60). É digno de nota que, apesar de apoiar-se na concepção wittgensteiniana de jogo de linguagem e de seguir uma regra - "um só e em uma única vez" não pode seguir uma regra -, que põe o acento na práxis, Apel tem de recorrer ao discernimento dos indivíduos participantes da comunidade real de comunicação a respeito desse a priori que constitui a comunidade ideal. O participante deve poder discernir a comunidade ideal "em seu autoentendimento pensante" [in seiner denkenden Selbstverständigung] (APEL, 1973a, 60).

Assim, embora tenha de recusar a figura do sujeito transcendental enquanto tal, Apel não prescinde da certeza autorreflexiva dos participantes da argumentação quanto ao a priori que os vincula individualmente à comunidade linguística. A pré-estrutura linguística tem de torna-se de algum modo transparente à consciência do indivíduo linguisticamente socializado. É nessa certeza do sujeito sobre si como ser de linguagem [Sprachwesen] (APEL, 1973b, 247) que podemos ancorar o propósito apeliano de alcançar "algo como um ponto cartesiano da fundamentação última da filosofia" (APEL, 1973a, 62). A formulação mais célebre possuir o seguinte teor:

Se eu não posso contestar algo sem autocontradição atual e ao mesmo tempo não posso fundamentar dedutivamente sem 
petitio principii lógico-formal, então isso pertence justamente àquelas pressuposições pragmático-transcendentais que é preciso ter reconhecido desde sempre, se o jogo de linguagem da argumentação deve manter seu sentido. Por isso, pode-se chamar esse modo de argumentação pragmáticotranscendental também de forma, crítica do sentido, da fundamentação última (APEL, 1998, 69).

Na linha da estratégia anticética, comum a Wittgenstein e à filosofia analítica (cf. STROUD, 1968, 242), as contradições performativas em que se enreda todo cético (o racionalista crítico no caso) ao negar os pressupostos pragmáticos da argumentação servem assim de canal para a formulação de uma nova ideia de fundamentação última. Ele se opera visando encontrar o fundamento na dúvida, como o sujeito cartesiano encontra o cogito como instância a respeito da qual toda dúvida é autocontraditória. A referência recorrente de Apel ao discurso cartesiano não é nada supérflua, ela é indicativa de algo maior: a filosofia a ser transformada, mas de certo modo conservada, é a prima philosophia, capaz de assegurar para si mesma os fundamentos últimos da razão e da compreensão do ser (HERRERO, 1997, 824). A fundamentação última é o sentido mais geral da reflexão transcendental:

quando nós, no contexto de uma discussão filosófica sobre fundamentos, constatamos que algo não pode ser em princípio fundamentado porque é a condição de possibilidade de toda fundamentação, então nós não constatamos simplesmente uma aporia no procedimento dedutivo, antes obtemos um discernimento sobre o sentido da reflexão transcendental (APEL, 1973d, 406).

Não cabe aqui pôr em questão até que ponto a ideia original de reflexão em Kant, ou seus diversos e intricados sentidos (cf. LIEDTKE, 1966; TORRES FILHO, 2008; FIGUEIREDO, 2016), sofre com isso uma forte e drástica redução. Reflexão vai além da crítica, do autoexame da razão sobre seus limites próprios, não é uma comparação de representações capaz de explicar sua própria unidade, a descoberta da regra e da fonte da regra como faculdade de conhecer e julgar ou ainda a operação de totalizar em função da experiência da razão; refletir é encontrar o fundamento para além do qual não se pode ir. A filosofia somente pode exercer a crítica se tiver fundamentado previamente seus parâmetros. Por isso, Apel não se cansa de insistir no teor do projeto de transformação da filosofia com base em Wittgenstein e Peirce: ela deve conservar, por meio de um equivalente, o "ponto mais alto" da dedução transcendental: "a síntese transcendental 
da apercepção" e o "princípio supremo dos juízos sintéticos", de acordo com o qual o "as condições da experiência são ao mesmo tempo as condições de possibilidade dos objetos da experiência" (APEL, 1973b, 224). Tal equivalente consiste, como se sabe, na unidade transcendental da linguagem, que confere sentido a toda argumentação real enquanto argumentação por ser uma estrutura "incontornável" [unhintergehbar] e, como tal, um fundamento último.

A reflexão transcendental parece ganhar assim ao menos duas coordenadas: de um lado, ele se assegura na autocontradição de quem renega os pressupostos da argumentação, que opera como um a priori último para todas as demais formas de argumentação. De outro lado, mas em uma camada não tão evidente, ela designa a própria certeza desse encontro do pensamento com a pré-estrutura da linguagem em si mesmo.

Esse segundo aspecto, que conserva algo do sentido da reflexão como operação do sujeito, parece se contrapor ao primeiro. Se o "problema da validade da verdade não pode mais ser visto como aquele da evidência ou certeza (certitudo)" (APEL, 1973c, 312), não caberia esperar um lugar considerável para a operação reflexiva do sujeito enquanto tal. Não é, porém, nenhum pouco incongruente que Apel lamente o fato "paradoxal" de que, na guinada da filosofia da consciência para a filosofia da linguagem em que se acomoda a transformação filosófica, "a reflexão pareça ter saído de moda ou mesmo se tornado sem sentido" (APEL, 1973, II, 313), no exato momento em que essa guinada pretende dar continuidade à crítica reflexiva do conhecimento. O que pode significar, afinal, uma reflexão sem sujeito? O preço a pagar para o abandono da instância última do sujeito epistemológico solitário, já insustentável, seria o abandono da própria pretensão da reflexão? Como a reflexão sobre a linguagem na linguagem é possível?

Ao responder a essas questões, o conceito de reflexão que Apel tem de mobilizar para seu projeto de fundamentação última não parece tão distante da tradição, mesmo porque ele está longe de pretender uma ruptura com ela: a reflexão

representa uma meditação (Besinnung), definitiva segundo a forma, do pensamento ligado à linguagem sobre si mesmo como condição de possibilidade de sua pretensão de validade. Como meditação transcendental, essa reflexão é, a meu ver, a autofundamentação possível para a filosofia (e não apenas para a filosofia) (APEL, 1973c, 326).

O pensamento enquanto tal se pensa no vínculo estruturante com a linguagem. 
Vê-se que, sem um conceito de reflexão como meditação do pensamento sobre si mesmo enquanto linguisticamente estruturado, não se pode alcançar, segundo Apel, uma fundamentação última para o a priori da comunicação. O pensamento se reflete na linguagem por meio da contradição performativa em que se enreda o ceticismo a respeito dessa estrutura da linguagem. Seria um equívoco, insiste Apel, reduzir o papel do elemento reflexivo, como aconteceu na história da filosofia analítica e, além dele, no estruturalismo.

O elemento reflexivo é inclusive determinante da dimensão pragmática do uso dos signos linguísticos, de modo que a exclusão dela, como sucede no modelo dedutivista de fundamentação defendido pela escola popperiana, especialmente por Hans Albert, leva ao resultado de que "não há sujeito humano da argumentação e, por isso, tampouco a possibilidade de uma reflexão sobre as condições de possibilidade da argumentação pressupostas desde sempre para nós" (APEL, 1973d, 406). Toda discussão sobre a possibilidade de fundamentação se vê perdida sem a "competência de reflexão do ser humano como sujeito de argumentação" (APEL, 1973d, 406).

Cumpre acrescentar, nesse aspecto, que Apel não reivindica aqui nenhuma acepção absolutamente nova de fundamentação última. De Aristóteles a Husserl, a fundamentação última jamais pode "ser compreendida como um problema puramente lógico-formal" (APEL, 1998, 40) ao qual se reduziu na formulação de Albert a propósito do trilema de Munchhausen (regresso infinitio, círculo lógico, e interrupção não fundamentada do procedimento de fundamentação). A escola popperiana é que inova ao retirar da questão da fundamentação o problema da evidência, que conferia à lógica um papel subordinado. O ponto consiste em deslocar a evidência para além dos limites da consciência, sem que, com isso, se perca a condição para o reconhecimento do significado da coerção lógica da contradição performativa. A evidência é um "discernimento reflexivo nos fundamentos não criticáveis da própria argumentação" (APEL, 1998, 69). O tipo de evidência se altera quando o sujeito do conhecimento é substituído pelo sujeito da argumentação, mas ela não deixa de ser uma "certeza indubitável" (APEL, 1998, 53) do pensamento, desempenhando o papel de completar a fundamentação a partir da contradição.

Sem a reflexão ou a meditação transcendental não é possível uma fundamentação última. Essa observação não pode ser tomada em um sentido trivial, como se o sujeito fosse coadjuvante de uma descoberta de fundamentos que não se encontram precipuamente nele, mas na linguagem. Nos termos de Apel, essa consideração seria típica do déficit de reflexão da filosofia analítica como tal. Ao contrário, somente porque o 
sujeito da argumentação pode refletir sobre si mesmo na linguagem, a linguagem aparece como fundamento último. Pode-se dizer que ele mesmo se revela a si mesmo com ser de linguagem [Sprachwesen].

Daí a remissão ao procedimento genético fichteano, de buscar a gênese autorreflexiva da facticidade da razão, em um nível cada vez mais alto, não ser tão surpreendente como sugere Habermas, para quem a "identificação reflexiva" de uma operação efetuada factualmente na argumentação seria um retorno às figuras da filosofia da consciência. "A partir do momento em que nos movemos no plano analítico da pragmática da linguagem, essa identificação nos é vedada" (HABERMAS, 1989c, 119). A crítica habermasiana é contundente, mas é preciso reconhecer que ela parte de si mesma, de uma concepção de racionalidade linguística que, na visão de Apel, seria deficitária em princípio quanto à necessária reflexão do sujeito sobre a linguagem na linguagem. Afinal, quem poderia se certificar de uma condição instransponível, incontornável, se não é o sujeito da argumentação enquanto sujeito ao mesmo tempo de pensamento e linguagem? A fundamentação última se assenta na contradição performativa, mas ela somente pode se completar na certeza do sujeito da argumentação que discerne o a priori da comunidade de comunicação que o vincula desde sempre a todos os sujeitos possíveis de toda argumentação possível.

O conceito apeliano de reflexão transcendental deve ser entendido assim como a operação, efetuado pelo sujeito da argumentação, de encontrar reflexivamente o fundamento último em que move pelo fio da evitação de autocontradições performativas até chegar ao grau de uma certeza indubitável. Com os fundamentos pragmático-transcendentais, obtêm-se os critérios por meio da qual a filosofia se diferencia da ciência e ao mesmo tempo a fundamenta, incluindo aí a própria lógica formal. Certamente, com os diversos paradigmas de filosofia primeira - metafísico, epistemológico ou semiótico -, alteram-se as condições em que o pensamento pode realizar a intenção de certificar-se de um "primeiro" e "último", mas todos eles coincidem no propósito.

II

Embora Habermas chame para si com menor visibilidade e frequência a tarefa de transformar a filosofia, ela percorre igualmente sua obra de maneira decisiva. Para se dar conta disso, basta verificar o longo esforço de encontrar uma resposta à questão jovem-hegeliana sobre a superação da filosofia, que, como tentei apontar anteriormente, impacta muito pouco o projeto apeliano. No caso de Habermas, o motivo jovem-hegeliano tem 
consequências de longo alcance porque, diferentemente de Apel, ele tem que se a ver com o papel da filosofia na Teoria Crítica, que de certo modo se constitui na relação problemática com a intenção de realizar a filosofia.

No campo de forças que bloqueiam a realização da filosofia, mas também impedem sua retomada como filosofia primeira, resta unicamente sua autocompreensão como crítica (HABERMAS, 1981, 2014a, 2014b). A filosofia primeira, na medida em que se entende como teoria pura, desligada de interesses, se vê sob a suspeita de ideologia (HABERMAS, 2014b, 196). Por outro lado, o cientificismo em que resultou também o materialismo se presta à mesma objeção. A filosofia se vê destinada assim a um exercício de crítica que mantém a pretensão enfática de verdade da tradição metafísica, orientando-se, no entanto, pelo conhecimento falível das ciências empíricas. De maneira geral, a crítica filosófica toma a forma da crítica da ideologia de matriz marxiana ou freudiana, da crítica do conhecimento como crítica da sociedade (HABERMAS, 2014a, 23-25).

Não cabe aqui reconstituir o longo processo por meio do qual Habermas revisa esse projeto, que é aquele de Conhecimento e interesse. Em seu resultado, Habermas pretende mostrar que a crítica da ideologia depende de um momento genuinamente teórico de fundamentação de padrões de racionalidade que trazem os critérios da crítica. Nisso consiste a distinção entre reconstrução racional e crítica da ideologia, proposta por Habermas no posfácio de Conhecimento e interesse (HABERMAS, 2014a, 491 ss.), ambas as ideias encarnando formas distintas de autorreflexão. Tampouco cabe aqui a reconstituição da revisão, igualmente longa, também dessa diferença, como se vê indiretamente no final da Teoria da ação comunicativa (HABERMAS, 1987b, 588 ss.). Em vez disso, contento-me unicamente em chamar a atenção para a continuidade do tema jovemhegeliano em um outro registro, para em seguida traçar os usos do conceito de reconstrução no conceito de filosofia.

Ora, o tema jovem-hegeliano da superação da filosofia não pode ser visto apenas como uma subordinação da reflexão filosófica ao projeto revolucionário de realizar a própria filosofia. Ela tampouco precisa ser respondida por meio de uma crítica cada vez mais autorreferente, como o "exercício vazio da autorreflexão, que se apoia nos objetos da própria tradição, sem se apoderar de uma única ideia sistemática", como Habermas tende a caracterizar a dialética negativa adorniana (HABERMAS, 1981, 3132). Na visão de Habermas, continuamos a ser contemporâneos dos jovens hegelianos na medida em que temos de renunciar às pretensões da filosofia primeira, seja lá qual for sua vertente.

A razão não é considerada nem como algo pronto, como uma teleologia objetiva que se manifesta na natureza ou na 
história, nem como uma mera faculdade subjetiva. Pelo contrário, os padrões estruturais detectados nos desenvolvimentos históricos propiciam os indícios cifrados sobre as veredas de processos de formação inconclusos, interrompidos ou mal conduzidos, que ultrapassam a consciência do indivíduo (HABERMAS, 2000, 78).

Vê-se que a ideia habermasiana de razão se distancia muito daquela envolvida na missão de uma fundamentação última. Ela impõe uma relação com a história que interdita a certeza transcendental como a que Apel reivindica para o sujeito de linguagem. Ao considerar a si mesmo como tributário do enraizamento histórico do pensamento, Habermas precisa dispor de seu conceito de reconstrução racional de um modo aparentemente mais modesto, mais voltado para o ganho de plausibilidade do que evidências últimas.

Se excluirmos a sua primeira tentativa de elaborar uma teoria da verdade como consenso (HABERMAS, 1984a), cuja inspiração apeliana é chamativa, vemos que já cedo Habermas vai discordar da orientação dada à reflexão transcendental. Em primeiro lugar, no texto metodologicamente relevante sobre a pragmática, o "transcendental" só pode significar a recorrência inevitável de determinadas estruturas na experiência cognitiva, na ação social, na argumentação, a qual se verifica nas tentativas de refutação (HABERMAS, 1984b, 360). Em outros termos, como Habermas vai afirmar em suas "Notas programáticas", as contradições performativas não podem ser a via de uma fundamentação última, já que elas são dependentes de vários atos de interpretação. Elas nos alertam sobre a falta de alternativas, por ora, a determinadas regras da argumentação:

a afirmação de que não há alternativa para um pressuposto dado, de que esse pressuposto pertence antes à camada das pressuposições inevitáveis, isto é, universais e necessárias, tem o status de uma suposição; ela precisa, como hipótese de lei, ser examinada em casos (HABERMAS, 1989c, 120).

A falta de alternativa deve ser comprovada por estudos empíricos, de modo que as tarefas filosóficas de fundamentar a ética se insere "no círculo das ciências reconstrutivas".

A defesa do falibilismo no interior de um projeto de fundamentar a ética do discurso não poderia soar mais dissonante aos ouvidos apelianos, uma vez que o modelo de fundamentação última visa, contra a escola popperiana, justamente mostrar que o falibilismo depende de uma instância não falível. Kuhlmann, por exemplo, se pergunta a fundamentação do 
falibilismo não pressupõe o que nega, ou seja, se Habermas não comete uma contradição performativa ao negar a possibilidade de um discurso transcendental forte, o único capaz de sustentar os direitos do falibilismo no campo da ciência, inclusive da ciência reconstrutivas (cf. KUHLMANN, 1986).

Porém, a posição habermasiana é ainda mais destoante no que diz respeito à linguagem. A linguagem não é algo que se possa fundamentar ela mesma, pois não se pode excluir a possibilidade de que nossa compreensão sobre ela se deva a jogos de linguagens certamente muito arraigados, mas não por isso menos factuais, como alerta Schönrich (1981, 190). "A falta de alternativa dessas regras fica provada para a prática da argumentação, sem que esta, porém, fique ela própria fundamentada" (HABERMAS, 1989c, 118). O fato de não se poder rejeitar factualmente, aqui e agora, os pressupostos pragmáticos da argumentação não significa que toda a práxis argumentativa esteja fundamentada de modo a priori, o que significa dizer: subtraída do tempo, não sujeita a alterações. Uma vez que essa práxis se entrelaça com a nossa própria forma de vida sociocultural, ela depende da constância dessa forma de vida. Assim, "não podemos excluir a priori a possibilidade de sua transformação" (HABERMAS, 1991, 195).

Portanto, se a filosofia deve se entender como uma teoria reconstrutiva da racionalidade, ela não pode se fundamentar em um sentido transcendental forte. $O$ transcendental se retrai na falta de alternativas, sob a pressão da busca de mais subsídios. Com isso, ela tem que se abrir às ciências, pois a filosofia continua dependente, na medida em que só pode contar com plausibilidades, dos estudos empíricos que fomentam ou refutam as hipóteses sobre a racionalidade comunicativa de modo geral.

Assim, o conceito de reconstrução racional se arma sobre uma estratégia de evitar a direção que Apel imprimiu aos argumentos transcendentais. A filosofia deve afastar qualquer tentativa de fundamentação das ciências e da cultura em geral:

A renúncia às fundamentações últimas de tipo tradicional ou crítico exige um preço que às vezes me rende a reprovação de ecletismo; eu me refiro à necessidade de ligar-se a abordagens reconstrutivas diversas e a tendências de pesquisa empírica correspondentes, com o objetivo de verificar se os resultados das ciências particulares se combinam sob os pontos de vista teóricos abrangentes e interessantes para mim. (...) Na medida em que a filosofia assume as tarefas de uma teoria da racionalidade, ela terá de esclarecer a compreensão descentrada do mundo do 
racionalismo ocidental que se formou na Europa da época moderna com a diferenciação das "esferas de valor" de ciência, moral e arte, igualmente com os ideais da sociedade civil e do estado democrático de direito (HABERMAS, 1984c, 506-507).

A teoria reconstrutiva da racionalidade deve mirar, portanto, não uma fundamentação da ciência, da moral e da arte na significação de um discurso capaz de definir de uma vez por todas o sentido dessas esferas de valor. Antes, ela deve reconstruir a lógica e a dinâmica de desenvolvimentos que levaram à compreensão moderna do mundo. Por lógica do desenvolvimento, Habermas se refere ao espaço lógico de padrões de racionalidade que servem de trilha para a dinâmica histórica, repleta de acidentes, sob a pressão constante da reprodução material da sociedade (HABERMAS, 1971, 175). Essa estratégia permite-lhe, por conseguinte, criar

um agudo contraste entre as possibilidades de orientação das estruturas de consciência modernas que resultaram do processo de desencantamento e o perfil das possibilidades realizadas a partir desse espectro e traduzidas efetivamente em instituições que caracteriza a sociedade capitalista (HABERMAS, 1987a, 46).

Se é assim, torna-se claro que o elemento reflexivo da reconstrução, por meio do qual o teórico pode discernir um padrão incontornável, não lhe dá certeza alguma, mas o lança para a compreensão do papel desse padrão no desenvolvimento histórico até e com a modernidade, atento também às suas insuficiências, como na crítica à modernização capitalista. A filosofia reconstrutiva só pode contar com o reforço científico da plausibilidade para a qual abrem caminho as reflexões a partir da instância discursiva.

Em vez de fundamentar de maneira transcendental, e com isso se arriscar na tarefa de um tribunal da razão, de indicar o lugar das esferas da cultura, Habermas propõe a noção de guardar lugar e interpretar (HABERMAS, 1989a). O papel de guardador de lugar, "mais modesto" que aquele do indicador, tem um aspecto defensivo, mas também agressivo, de vanguarda. A filosofia guarda o lugar de teorias que ainda não encontraram o devido respaldo na divisão de trabalho do conhecimento, ou seja, a filosofia protege as hipóteses de reconstrução com forte pretensão universalista. Por outro lado, isso implica também em tentar avançar para além do status quo científico. A filosofia guarda lugar e estimula as investigações com novas perspectivas. Ela deve poder reconhecer onde se 
dão os avanços cognitivos mais significativos diante do diagnóstico da modernidade. Nos dois aspectos, a própria filosofia não tem um papel fixo, um lugar próprio definitivo. É isso que caracteriza a natureza anárquica do discurso filosófico, no interior de uma divisão de trabalho "não-exclusivista".

Além desse papel de guardador de lugar, a filosofia deve desempenhar o papel de mediador-intérprete, seja entre as esferas de valor, e sobretudo entre elas e os mundos da vida das sociedades modernas. A diferenciação entre ciência, arte, moral e direito ocorreu sem a intervenção da filosofia, mas ela suscita o problema filosófico de constituir uma rede de passagens mediadoras (cf. TERRA, 2003, 22), sem qual se abre o abismo da fragmentação e do empobrecimento cultural. A unidade da razão procedimental, desprovida de uma reflexão que garante a si mesmo sua identidade, só pode contar com a "possibilidade fundamental de uma passagem, como sempre ocasional, porém compreensível, de uma linguagem a outra" (HABERMAS, 1988, 155). Habermas atribui à filosofia uma capacidade única de interpretar e traduzir linguagens especializadas em outras, e de todas elas para a linguagem espontânea do mundo da vida. Ele a caracteriza como uma capacidade hermenêutica de "transgredir os limites da linguagem e do discurso, enquanto ao mesmo tempo permanece sensível aos contextos holísticos do pano de fundo" (HABERMAS, 2004, 356). Tal capacidade hermenêutica pode se fundar na própria história da filosofia, mas tem que ser preservada pela cooperação da filosofia com as ciências e com as artes de modo geral. Ao guardar lugar para as teorias mais avançadas, o filósofo regenera sua capacidade mediar, interpretar e traduzir. Em sentido inverso, quanto mais a filosofia quer manter para si um lugar bem delimitado, ela perde a capacidade de mediação.

Dessa maneira, vale a pena insistir, os papeis filosóficos de guardar lugar estão intrinsecamente ligados à sua compreensão de reconstrução racional. As operações reflexivas da reconstrução não se direcionam para um terreno a partir do qual poderia se deslindar das contribuições da ciência e das artes, fundamentando-as, mas de estabelecer contornos, espaços lógicos, potencialidades.

\section{***}

Sem a pretensão de esgotar o que está envolvido nessas diferenças entre reconstrução e reflexão a propósito do conceito de filosofia, é possível expressar, baseando-se no percurso tomado, uma certa surpresa quanto a difundida representação de Apel e Habermas como defensores de um projeto comum (cf. exemplarmente GIANNOTTI, 1991). Não se trata, aqui, de apontar incoerências e contradições nos respectivos programas. De Apel 
não se pode desconfiar nenhuma mudança de rota, mas antes um refinamento contínuo no intento de restaurar a filosofia primeira por um conceito de reflexão transcendental como fundamentação última. A base pragmática desse intento não o empurra para fora da filosofia primeira, como quer Habermas, mas antes Ihe fornece uma nova ferramenta para um propósito admitidamente tradicional.

Por sua vez, Habermas recupera sem dúvida algo das pretensões filosóficas de constituir uma teoria da racionalidade, mas o trajeto que vai da filosofia como crítica da ideologia até a filosofia como ciência reconstrutiva imprime à ideia de reconstrução um conceito pouco usual de filosofia, ao menos na sua relação com as ciências, com a cultura e com o tempo histórico. É difícil encontrar na tradição exemplos desses papeis de guardador de lugar para teorias científicas ainda não estabelecidas e de mediar as diversas esferas de saber entre si e com o mundo da vida.

Por outro lado, e por fim, não convém aceitar sem mais a autodescrição habermasiana como projeto "mais modesto". O grau de exigência que semelhantes tarefas implicam para filosofia destoa consideravelmente das capacidades filosóficas em voga há muito tempo. Habermas talvez seja o único filósofo que corresponde às pretensões postas por ele mesmo. Não há modéstia, de fato. Por sua vez, Apel não esconde seu perfil mais tradicional e, assim, realmente modesto. Ao assegurar uma evidência a partir da lógica pragmática da argumentação, ele envolve o sujeito de linguagem nos seus parcos recursos: a certeza reflexiva. 


\section{Notas}

1 Professor Associado da Universidade de São Paulo. E-mail: luizrepa@usp.br; Orcid-ID: https://orcid.org/0000-0002-8538-3797.

2 A seguir, as citações dos textos de Apel traduzem diretamente o original em alemão: Transformation der Philosophie (APEL, 1973a, 1973b, 1973c, 1973d); Das Problem der philosophischen Letzbegründung im Lichte einer transzendentalen Sprachpragmatik. Versuch einer Metakritik des "kritischen Rationalismus" (APEL, 1998). Em relação a Habermas, as citações do original em alemão se referem a: Wozu noch Philosophie? (HABERMAS, 1981); Erläuterungen zur Diskursethik (1991); Replik auf Einwände (1984); Theorie des kommunikativen Handelns (1987a). 


\section{Referências bibliográficas}

APEL, Karl-Otto. Einleitung: Tranformation der Philosophie. In: Transformation der Philosophie. Band 1. Sprachanalytik, Semiotik, Hermeneutik. Frankfurt am Main: Suhrkamp, 1973a.

APEL, Karl-Otto. Die Kommunikationsgemeinschaft als transzendentale Voraussetzung der Sozialwissenschaften. In: Transformation der Philosophie. Band 2 - Das Apriori der Kommunikationsgemeinschaft. Frankfurt am Main: Suhrkamp, 1973b.

APEL, Karl-Otto. Sprache als Thema und Medium der transzendentalen Reflexion. In: In: Transformation der Philosophie. Band 2 - Das Apriori der Kommunikationsgemeinschaft. Frankfurt am Main: Suhrkamp, 1973c.

APEL, Karl-Otto. Das Apriori der Kommunikationsgemeinschaft und die Grundlagen der Ethik - Zum Problem einer rationale Begründung der Ethik im Zeitalter der Wissenschaft. In: Transformation der Philosophie. Band 2 - Das Apriori der Kommunikationsgemeinschaft. Frankfurt am Main: Suhrkamp, 1973d.

APEL, Karl-Otto. Vorwort zu Paradigmen der Ersten Philosophie: Zur reflexiven - transzendentalpragmatischen - Rekonstruktion der Philosophiegeschichte. Frankfurt am Main: Suhrkamp, 1985.

APEL, Karl-Otto. The Transcendental Conception of Language Communication and the Idea of a First Philosophy: towards a Critical Reconstruction of the History of Philosophy in the Light of Language Philosophy. In: MENDIETA, Eduardo. Karl-Otto Apel: Selected Essays. New Jersey: Humanity Press, 1994a.

APEL, Karl-Otto. Transcendental Semiotics as First Philosophy. In: MENDIETA, Eduardo. Karl-Otto Apel: Selected Essays. New Jersey: Humanity Press, 1994b.

APEL, Karl-Otto. Das Problem der philosophischen Letzbegründung im Lichte einer transzendentalen Sprachpragmatik. Versuch einer Metakritik des "kritischen Rationalismus". In: Auseinandersetzungen: in Erprobung des Transzendental-Pragmatischen Ansatzes. Frankfurt am Main: Suhrkamp, 1998.

FIGUEIREDO, Vinicius de. Reflexão na Crítica da razão pura. In: Studia Kantiana, v. 20, 2016.

GIANNOTTI, J. A. Habermas: mão e contramão. In: Novos estudos, n. 31. São Paulo: CEBRAP, 1991. 
HABERMAS, Jürgen, Wozu noch Philosophie? In: Philosophisch-politische Profile. Frankfurt am Main: Suhrkamp, 1981.

HABERMAS, Jürgen. Der Universalitätsanspruch der Hermeneutik. In: Zur Logik der Sozialwissenschaften. Frankfurt am Main: Suhrkamp, 1982.

HABERMAS, Jürgen, Wahrheitstheorien. In: Vorstudien und Ergänzungen zur Theorie des kommunikativen Handelns. Frankfurt am Main: Suhrkamp, $1984 a$.

HABERMAS, Jürgen, Was heisst Universalpragmatik? In: Vorstudien und Ergänzungen zur Theorie des kommunikativen Handelns. Frankfurt am Main: Suhrkamp, 1984b.

HABERMAS, Jürgen, Replik auf Einwände. Vorstudien und Ergänzungen zur Theorie des kommunikativen Handelns. Frankfurt am Main: Suhrkamp, 1984c.

HABERMAS, Jürgen, Theorie des kommunikativen Handelns. Vol. I. Frankfurt am Main: Suhrkamp, 1987a.

HABERMAS, Jürgen, Theorie des kommunikativen Handelns. Vol. II. Frankfurt am Main: Suhrkamp, 1987b.

HABERMAS, JÜRGEN, Die Einheit der Vernunft in der Vielfalt ihrer Stimmen. Frankfurt am Main: Suhrkamp, 1988.

HABERMAS, Jürgen. A filosofia como guardador de lugar e como intérprete. In: Consciência moral e agir comunicativo. Trad. Guido de Almeida. Rio de Janeiro: Tempo Brasileiro, 1989a.

HABERMAS, Jürgen, Ciências sociais reconstrutivas versus ciências sociais compreensivas. Consciência moral e agir comunicativo. Trad. Guido de Almeida. Rio de Janeiro: Tempo Brasileiro, 1989b.

HABERMAS, Jürgen. Notas programáticas para a fundamentação de uma ética do discurso. In: Consciência moral e agir comunicativo. Trad. Guido de Almeida. Rio de Janeiro: Tempo Brasileiro, 1989c.

HABERMAS, Jürgen. Erläuterungen zur Diskursethik. In: Erläuterungen zur Diskursethik. Frankfurt am Main: Suhrkamp, 1991.

HABERMAS, Jürgen. Três perspectivas: hegelianos de esquerda, hegelianos de direita e Nietzsche. In: O discurso filosófico da modernidade. Trad. Luiz Repa, Rodnei Nascimento. São Paulo: Martins Fontes, 2000. 
HABERMAS, Jürgen. Noch einmal: Zum Verhältnis von Theorie und Praxis. In: Wahrheit und Rechtfertigung. Philosophische Aufsätze. Frankfurt am Main: Suhrkamp, 2004.

HABERMAS, Jürgen. Entre filosofia e ciência: marxismo como crítica. In: Teoria e práxis. Trad. Rúrion Melo, 2013.

HABERMAS, Jürgen. Conhecimento e interesse. Trad. Luiz Repa. São Paulo: Ed. Unesp, 2014a.

HABERMAS, Jürgen. Conhecimento e interesse. In: Técnica e ciência como "ideologia". Trad. Felipe Gonçalves Silva. São Paulo: Ed. Unesp, 2014b.

HABERMAS, Jürgen. A inclusão do outro: estudos de teoria política. Trad. Denílson Luís Werle. São Paulo: Ed. Unesp, 2018.

HERRERO, F. Javier. A pragmática transcendental como "filosofia primeira". In: Veritas, v. 42, n. 4, 1997.

HORKHEIMER, Max. Filosofia e teoria crítica. In: BENJAMIN, Walter et alii. Textos escolhidos. Trad. Edgard Afonso Malagodi, Ronaldo Pereira Cunha. São Paulo: Abril Cultural, 1975.

KORSCH, Karl. Marxismo e filosofia. In: Marxismo e filosofia. Trad. José Paulo Neto. Rio de Janeiro: Ed. UFRJ, 2008.

KUHLMANN, Wolfgang, Philosophie und Rekonstruktive Wissenschaft. In: Zeitschrift für philosophische Forschung, n. 40, 1986.

LIEDTKE, Max. Der Begriff der Reflexion bei Kant. In: Archiv für Geschichte der Philosophie, v. 48, n. 1-3, 1966.

MARK, Karl. Zur Kritik der Hegelschen Rechtsphilosophie. Einleitung. In: Marx Engels Werke, vol. I. Berlin: Dietz Verlag, 1970.

NOBRE, Marcos. "Permanecemos Contemporâneos dos Jovens Hegelianos": Jürgen Habermas e a situação de consciência atual. In: Revista Olhar, ano 2, v. 4, 2000.

SCHÖNRICH, Gerhard. Kategorien und transzendentale Argumentation. Kant und die Idee einer transzendentalen Semiotik. Frankfurt am Main, Suhrkamp, 1981.

STROUD, Barry. Transcendental Arguments. In: The Journal of Philosophy, vol. LXV, N.o 9, maio de 1968.

TERRA, Ricardo. Passagens. Estudos sobre a filosofia de Kant. Rio de Janeiro: Ed. UFRJ, 2003. 
TORRES FILHO, Rubens Rodrigues. A terceira margem da filosofia de Kant. In: PERES, Daniel Tourinho et alii. Tensões e passagens: filosofia crítica e modernidade - Uma homenagem a Ricardo Terra. São Paulo: Esfera Pública, 2008. 